B. В. Масляков и др. Изменения показателей тромбоэластограммы при базальноклеточном раке кожи в послеоперационном периоде

УДК 616-006.63

DOI: $10.18101 / 2306-1995-2019-1-23-30$

\title{
ИЗМЕНЕНИЯ ПОКАЗАТЕЛЕЙ ТРОМБОЭЛАСТОГРАММЫ ПРИ БАЗАЛЬНОКЛЕТОЧНОМ РАКЕ КОЖИ В ПОСЛЕОПЕРАЦИОННОМ ПЕРИОДЕ
}

\section{(C) Масляков Владимир Владимирович}

доктор медицинских наук, профессор, проректор по научной работе частного образовательного учреждения высшего образования

«Саратовский медицинский университет "Реавиз"»

Россия, 410012, Саратов, ул. Верхний Рынок, корпус 10

E-mail: maslyakov@inbox.ru

\section{(C) Гребнев Дмитрий Юрьевич}

доктор медицинских наук, доцент, заведующий кафедрой патологической физиологии, Уральский государственный медицинский университет Россия, 620028, Екатеринбург, ул. Репина, 3

E-mail: usma@usma.ru

\section{(C) Ким Лариса Михайловна}

аспирант,

кафедра клинической медицины частного образовательного учреждения

высшего образования

«Саратовский медицинский университет "Реавиз"»

Россия, 410012, Саратов, ул. Верхний Рынок, корпус 10

E-mail: saratov@reaviz.ru

\section{(C) Шабаева Зульфия Искандеровна}

аспирант,

кафедра клинической медицины частного образовательного учреждения

высшего образования

«Саратовский медицинский университет "Реавиз"»

Россия, 410012, Саратов, ул. Верхний Рынок, корпус 10

E-mail:saratov@reaviz.ru

Работа основана на анализе течения заболевания у 76 пациентов с различными образованиями кожи, которым было проведено исследование тромбоэластограммы кровяной плазмы. В результате проведенного исследования было установлено, что периферической крови установлено, что в патогенезе развития базальноклеточного рака кожи важное значение отводится процессам изменения процессов свертывания в крови и изменениям динамики процессов по изменению вязкости и упругости формирующегося сгустка. Проведение исследование показателей тромбоэластограммы кровяной плазмы, взятой у больных, страдающих базальноклеточным раком кожи, перед началом операции отмечался гиперкоагуляционный синдром, что подтверждалось резким увеличением индекса коагуляции, тромбодинамического потенциала, максимальной амплитуды и эластичности сгустка. При этом выполнение оперативного лечения не приводит к восстановлению данных показателей, все это следует иметь в виду в лечении больных с этой патологией.

Ключевые слова: базальноклеточный рак кожи, тромбоэластограмма. 
Для цитирования:

Масляков В. В., Гребнев Д. Ю., Ким Л. М., Шабаева 3. И. Изменения показателей тромбоэластограммы при базальноклеточном раке кожи в послеоперационном периоде // Вестник Бурятского государственного университета. Медицина и фармация. 2019. Вып. 1. С. 23-30.

Введение. По результатам мировой статистики за последние десять лет происходит бурное развитие онкологической патологии, в том числе поражение кожных покровов. При этом в ряде стран эта патология заняла одно из первых мест. Например, в такой стране, как Германия рак данной локализации у мужской части населения занимает второе место после рака легкого, а среди женского населения, рак кожи находится на втором месте после рака молочных желез, показатели данной патологии составляют соответственно 93,4 и 55,8 на 100 тысяч населения. Согласно результатом общества дерматологов Германии, численность заболевших раком кожи удваивается каждые 15 лет [5]. Базальноклеточный рак кожи (БКР) - это злокачественная эпителиальная опухоль с местнодеструирующим ростом, кроме того данная опухоль редко метастазирует [1]. На определение методики терапии БКР оказывает влияние гистологический тип, клиническая форма, ее локализация возрастные характеристики [4]. Доказано, что в патогенезе развития этого заболевания немаловажная роль отводится нарушениям показателям микроциркуляции и иммунного статуса $[2,3]$.

Вместе с тем остается множество нерешенных вопросов связанных с патогенезом этого заболевания, один из них — изменения тромбоэластограммы.

Цель исследования. Изучить изменения в показателях тромбоэластограммы у пациентов с базальноклеточным раком в послеоперационном периоде.

Материалы и методы. Работа основана на анализе течения заболевания у 76 пациентов с различными образованиями кожи, находившихся на амбулаторном и стационарном лечении в лечебных учреждениях гг. Энгельс и Саратов в период с 2015 по 2017 годы, возраст которых составил $65 \pm 3$ лет. Все пациенты были разделены на три группы: первая включила в себя 39 больных, которым был установлен диагноз БКР. Кроме основной группы были взяты две группы сравнения: первая группа сравнения включала в себя 17 доноров без выявленной патологии (І группа сравнения). Для сравнения была сформирована еще одна группа, куда вошли 20 человек, с доброкачественными образованиями кожи дерматофибромами (II группа сравнения). Группа сравнения и основная группа были сопоставимы по полу и возрасту.

Максимальное число как злокачественных, так и доброкачественных образований, по поводу которых обращались пациенты (25\%) располагались на нижних конечностях. В области лица было выявлено $15 \%$ различных образований. Считаем необходимым подчеркнуть, что в большинстве наблюдений были установлен базальноклеточный рак.

Диагноз устанавливался на основе предъявленных жалоб, анамнеза развития заболевания, для подтверждения диагноза применялась лабораторная диагностика. В качестве, которой применялись взятие соскоба на цитологическое исследование и выполнение биопсии образования, полученные образцы окрашивали гематоксилин-эозином

В исследование включались пациенты, у которых онкологический процесс соответствовал T1-2N0M0 по системе TNM. 
B. В. Масляков и $\partial$. Изменения показателей тромбоэластограммы при базальноклеточном раке кожи в послеоперационном периоде

Не включались те пациенты, у которых было выявлены образования Т34N0M0, а также те пациенты, которым была выполнена лучевая и/или применялась химиотерапия.

При проведении гистологического исследования было установлено, что при БКР преобладали поверхностные формы (75\%), узловая форма БКР была выявлена в $25 \%$ наблюдений.

Исследования выполнялись до начала операции, затем в первые, третьи, пятые, седьмые, десятые сутки после выполненной операции и спустя 18 месяцев.

Обследованным не назначались лекарственные вещества, способные оказывать влияние на свертывание крови.

Всем пациентам со злокачественными и доброкачественными образованиями кожи было выполнено оперативное лечение, объем которого зависел от характера опухоли. При фибромах проводилось удаление опухоли под местной анестезией, при базальноклеточном раке кожи - иссечение образования под местной анестезией с соблюдением онкологических принципов. Окончательный диагноз ставился после получения морфологического подтверждения.

Исследования тромбоэластограммы цитратной плазмы крови проводили на агрегатометре Agg RAm, производства Helena Laboratories, Англия; тромбоэластограмму (ТЭГ) проводили на тромбоэластографе HELLIGE, производства Германии. Выполнялись исследования гемостаза в тесте внешнего пути гемостаза EXTЕМ, который показывает процесс свертывания крови, активируемый тканевым фактором. Изучались следующие показатели: скорость образования тромба (угол $\alpha$ ); амплитуда плотности сгустка на 10-й минуте (А10, обусловлена фибрином и его свойствами) и 20-й минуте (А20); показатель максимальной плотности сгустка - MCF, который характеризует стабилизацию сгустка полимеризированным фибрином, тромбоцитами и XIII фактором, он является точкой, после которой запускаются тромболитические механизмы.

Статистическая обработка выполнялась на компьютере, где определялась достоверность различий (р). Использовалась прикладная программа "Statistica 6.0" и Excel (Microsoft, 2003).

Результаты и обсуждение. Как показывает проведенное исследование до выполнения операции при БКР был зарегистрирован тромбоцитоз. Так, у относительно здоровых пациентов количество тромбоцитов в периферической крови составило 340 $\pm 1,2 \times 10 \% /$, а в основной группе $-476 \pm 1,3 \times 10 \% /$ л $<<0,05)$. Одновременно с этим отмечалась повышенная агрегационная активность тромбоцитов, индуцированных АДФ $\left(5 \times 10^{-6} \mathrm{M}\right)$, в группе обследованных без выявленной патологии этот показатель составил $81,5 \pm 0,6 \%$, в основной группе этот показатель составил $97,4 \pm 0,3 \%(\mathrm{p}<$ $0,05)$. При этом в группе обследованных с доброкачественным образованием кожных покровов полученные результаты отличались от аналогичных результатов, полученных в группе со злокачественными образованиями кожи, это проявилось тем, что в данной группе количество тромбоцитов периферической крови соответствовал величинам, полученным в группе в группе обследованных без выявленной патологии $342 \pm 1,2 \times 10$ 9/л ( $>0,05)$.

Проводились исследования следующих показателей: индекс коагуляции (ИК), тромбодинамический потенциал (ТП), максимальная амплитуда (МА), эластичность сгустка (ЭС). Полученные результаты также свидетельствовали о гиперкоагуляционной активности, что подтверждалось резким увеличением показателей ИК, который в группе БКР составил $4,7 \pm 0,1$; в группе с доброкаче- 
ственными образованиями кожи $-1,03 \pm 0,3$, в группе обследованных без выявленной патологии $-1,05 \pm 0,3$. ТП в группе с БКР $117,6 \pm 0,3$ ед. изм.; в группе с доброкачественными образованиями кожи $-8,6 \pm 0,1$ ед. изм.; а в группе относительно здоровых людей $-8,4 \pm 0,2$ ед. изм. МА в группе с БКР составил $86,5 \pm$ 0,2 ; в группе с доброкачественными образованиями кожи $-56,5 \pm 0,4$; а в группе относительно здоровых людей $-57,3 \pm 0,2$. Показатель ЭС в группе с БКР составил $240 \pm 0,3$ мм; в группе с доброкачественными образованиями кожи $152 \pm 0,4$ мм, а у относительно здоровых людей $-148,5 \pm 0,2$ мм. Отсюда следует, что полученные показатели были статистически достоверно $(\mathrm{p}<0,05)$ повышены в группе с БКР как по сравнению с данными относительно здоровых людей, так и с данными пациентов с доброкачественными образованиями кожи. Кроме того, исследование ТЭГ цитратной плазмы крови показало отсутствие гиперкоагуляционной активности, т. к. все исследуемые показатели тромбоэластограммы находились в пределах физиологически нормальных величин, полученных в группе сравнения из относительно здоровых людей.

При проведении тромбоэластограммы цитратной плазмы крови у больных с БКР выявлены следующие изменения в тесте внешнего пути гемостаза EXTEM.

Полученные результаты до начала оперативного лечения представлены в таблице 1.

\section{Таблийа 1}

Показатели ТЭГ цитратной плазмы крови у пациентов основной группы и группы сравнения до начала операционного лечения $(\mathrm{M} \pm \mathrm{m})$

\begin{tabular}{|l|l|l|l|}
\hline \multirow{2}{*}{$\begin{array}{l}\text { Исследуемые пока- } \\
\text { затели крови }\end{array}$} & Результаты в группах & \multicolumn{3}{|l|}{} \\
\cline { 2 - 4 } & Основная $(\mathrm{n}=39)$ & группа $1(\mathrm{n}=17)$ & группа 2 $(\mathrm{n}=20)$ \\
\hline Угол $\dot{\alpha}$ & $97 \pm 0,3^{*}$ & $75 \pm 0,3^{\circ}$ & $73 \pm 0,3^{\circ}$ \\
\hline $\mathrm{A} 10, \mathrm{~mm}$ & $88 \pm 0,4^{*}$ & $47,4 \pm 0,2$ & $49,6 \pm 0,1$ \\
\hline $\mathrm{A} 20, \mathrm{~mm}$ & $93 \pm 0,6^{*}$ & $62 \pm 0,2$ & $64 \pm 0,8$ \\
\hline $\mathrm{MCF}, \mathrm{mm}$ & $84 \pm 0,5^{*}$ & $54,6 \pm 0,2$ & $55,5 \pm 0,4$ \\
\hline
\end{tabular}

Примечание: здесь и далее * - знак, показывающий статистическую достоверность $(\mathrm{p}<0,05)$.

Представленные в таблице 1 данные показывают, что в группе с БКР перед началом операции происходило повышение всех данных. Одновременно с эти в группе с доброкачественным образованием, полученные показатели не отличались от результатов, полученных в группе обследованных без выявленной патологии. Из этого следует, что в группе больных с БКР происходят изменения, которые можно охарактеризовать как гиперкоагуляционные.

Полученные результаты ТЭГ в первые сутки после выполнения операции, было выявлено, у пациентов как БКР так и с фибромой кожи, существенных изменений в показателях ТЭГ не было выявлено (табл. 2). 
B. В. Масляков и др. Изменения показателей тромбоэластограммы при базальноклеточном раке кожи в послеоперационном периоде

Таблицьа 2

Показатели ТЭГ цитратной плазмы крови у пациентов основной группы и группы сравнения в первые послеоперационные сутки $(\mathrm{M} \pm \mathrm{m})$

\begin{tabular}{|l|l|l|l|}
\hline \multirow{2}{*}{$\begin{array}{c}\text { Исследуемые показатели } \\
\text { крови }\end{array}$} & \multicolumn{3}{|c|}{ Результаты в группах } \\
\cline { 2 - 4 } & \multicolumn{1}{|c|}{ Основная $(\mathrm{n}=39)$} & \multicolumn{1}{|c|}{ группа 1 $(\mathrm{n}=17)$} & \multicolumn{1}{|c|}{ группа 2 $(\mathrm{n}=20)$} \\
\hline Угол $\alpha$ & $98 \pm 0,3^{\text {** }}$ & $75 \pm 0,3$ & $74 \pm 0,3$ \\
\hline $\mathrm{A} 10, \mathrm{~mm}$ & $89 \pm 0,4^{*}$ & $47,4 \pm 0,2$ & $49,6 \pm 0,1$ \\
\hline $\mathrm{A} 20, \mathrm{~mm}$ & $95 \pm 0,6^{*}$ & $62 \pm 0,2$ & $66 \pm 0,8$ \\
\hline $\mathrm{MCF}, \mathrm{mm}$ & $87 \pm 0,5^{*}$ & $54,6 \pm 0,2$ & $56,1 \pm 0,4$ \\
\hline
\end{tabular}

На третьи послеоперационные сутки в обеих группах было зарегистрировано статистически достоверное увеличение всех исследуемых показателей (табл. 3).

Таблий 3

Показатели ТЭГ цитратной плазмы крови у пациентов основной группы и группы сравнения на третьи послеоперационные сутки $(\mathrm{M} \pm \mathrm{m})$

\begin{tabular}{|l|l|l|l|}
\hline \multirow{2}{*}{ Исследуемые показатели крови } & \multicolumn{3}{|c|}{ Результаты в группах } \\
\cline { 2 - 4 } & \multicolumn{1}{|c|}{ Основная $(\mathrm{n}=39)$} & \multicolumn{1}{|c|}{ группа 1 $(\mathrm{n}=17)$} & группа 2 $(\mathrm{n}=20)$ \\
\hline Угол $\dot{\alpha}$ & $110 \pm 0,3^{\circ *}$ & $75 \pm 0,3^{\circ}$ & $94 \pm 0,3^{* *}$ \\
\hline $\mathrm{A} 10, \mathrm{~mm}$ & $98 \pm 0,4^{* *}$ & $47,4 \pm 0,2$ & $86 \pm 0,4^{*}$ \\
\hline $\mathrm{A} 20, \mathrm{~mm}$ & $113 \pm 0,6^{* *}$ & $62 \pm 0,2$ & $93 \pm 0,6^{*}$ \\
\hline $\mathrm{MCF}, \mathrm{mm}$ & $104 \pm 0,5^{* *}$ & $54,6 \pm 0,2$ & $84 \pm 0,5^{*}$ \\
\hline
\end{tabular}

К пятым послеоперационным суткам у пациентов со злокачественными образованиями кожи особенных изменений в исследуемых показателях не получено, а в группе больных с фибромой кожи происходило восстановление всех исследуемых показателей, данные показатели восстановились и не отличались от результатов, полученных перед началом операции. Результаты представлены в таблице 4.

Таблицุа 4

Показатели ТЭГ цитратной плазмы крови у пациентов основной группы и группы сравнения на пятые послеоперационные сутки $(\mathrm{M} \pm \mathrm{m})$

\begin{tabular}{|l|l|l|l|}
\hline \multicolumn{1}{|c|}{$\begin{array}{c}\text { Исследуемые показатели } \\
\text { крови }\end{array}$} & \multicolumn{3}{|c|}{ Результаты в группах } \\
\cline { 2 - 4 } & \multicolumn{1}{|c|}{ Основная $(\mathrm{n}=39)$} & \multicolumn{1}{|c|}{ группа 1 $(\mathrm{n}=17)$} & \multicolumn{1}{c|}{ группа 2 $(\mathrm{n}=20)$} \\
\hline Угол $\dot{\alpha}$ & $112 \pm 0,3^{\circ *}$ & $75 \pm 0,3^{\circ}$ & $74 \pm 0,3^{\circ}$ \\
\hline $\mathrm{A} 10, \mathrm{~mm}$ & $99 \pm 0,4^{*}$ & $47,4 \pm 0,2$ & $48,8 \pm 0,1$ \\
\hline $\mathrm{A} 20, \mathrm{~mm}$ & $114 \pm 0,6^{*}$ & $62 \pm 0,2$ & $65 \pm 0,8$ \\
\hline $\mathrm{MCF}, \mathrm{mm}$ & $106 \pm 0,5^{*}$ & $54,6 \pm 0,2$ & $54,8 \pm 0,4$ \\
\hline
\end{tabular}

К седьмым суткам после операции, изменений показателей ТЭГ выявлено не было. Полученные результаты не претерпевали существенных изменений по сравнению с данными пятых суток после операции (табл. 5). 
Показатели ТЭГ цитратной плазмы крови у пациентов основной группы и группы сравнения на седьмые послеоперационные сутки $(\mathrm{M} \pm \mathrm{m})$

\begin{tabular}{|l|l|l|l|}
\hline \multirow{2}{*}{$\begin{array}{c}\text { Исследуемые показатели } \\
\text { крови }\end{array}$} & \multicolumn{3}{|c|}{ Результаты в группах } \\
\cline { 2 - 4 } & \multicolumn{1}{|c|}{ Основная $(\mathrm{n}=39)$} & \multicolumn{1}{|c|}{ группа 1 $(\mathrm{n}=17)$} & \multicolumn{1}{c|}{ группа 2 $(\mathrm{n}=20)$} \\
\hline Угол $\alpha$ & $112 \pm 0,3^{\circ *}$ & $75 \pm 0,3^{\circ}$ & $74 \pm 0,3^{\circ}$ \\
\hline $\mathrm{A} 10, \mathrm{~mm}$ & $99 \pm 0,4^{*}$ & $47,4 \pm 0,2$ & $48,8 \pm 0,1$ \\
\hline $\mathrm{A} 20, \mathrm{~mm}$ & $114 \pm 0,6^{*}$ & $62 \pm 0,2$ & $65 \pm 0,8$ \\
\hline $\mathrm{MCF}, \mathrm{mm}$ & $106 \pm 0,5^{*}$ & $54,6 \pm 0,2$ & $54,8 \pm 0,4$ \\
\hline
\end{tabular}

К десятым суткам после выполненной операции у обследованных пациентов со злокачественными образованиями кожи было зарегистрировано уменьшение всех показателей ТЭГ. Полученные результаты восстанавливались и не отличались от данных полученных до выполнения операции. У пациентов с доброкачественными образованиями кожи, результаты ТЭГ не изменялись (табл. 6).

Показатели ТЭГ цитратной плазмы крови у пациентов с БКР на десятые послеоперационные сутки $(\mathrm{M} \pm \mathrm{m})$

\begin{tabular}{|l|l|l|l|}
\hline \multirow{2}{*}{$\begin{array}{c}\text { Исследуемые показатели } \\
\text { крови }\end{array}$} & \multicolumn{3}{|c|}{ Результаты в группах } \\
\cline { 2 - 4 } & \multicolumn{1}{|c|}{ Основная $(\mathrm{n}=39)$} & \multicolumn{1}{|c|}{ группа 1 $(\mathrm{n}=17)$} & \multicolumn{1}{|c|}{ группа 2 $(\mathrm{n}=20)$} \\
\hline Угол $\alpha$ & $98 \pm 0,3^{\circ *}$ & $75 \pm 0,3^{\circ}$ & $74 \pm 0,3^{\circ}$ \\
\hline $\mathrm{A} 10, \mathrm{~mm}$ & $89 \pm 0,4^{*}$ & $47,4 \pm 0,2$ & $48,8 \pm 0,1$ \\
\hline $\mathrm{A} 20, \mathrm{~mm}$ & $95 \pm 0,6^{*}$ & $62 \pm 0,2$ & $65 \pm 0,8$ \\
\hline $\mathrm{MCF}, \mathrm{mm}$ & $86 \pm 0,5^{*}$ & $54,6 \pm 0,2$ & $54,8 \pm 0,4$ \\
\hline
\end{tabular}

При исследовании ТЭГ через восемнадцать месяцев после операции, все исследуемые показатели существенно, статистически достоверно не отличались от данных, полученных на десятые послеоперационные сутки (табл. 7).

Таблица 7

Показатели ТЭГ цитратной плазмы крови у пациентов основной группы и группы сравнения в отдаленном послеоперационном периоде $(\mathrm{M} \pm \mathrm{m})$

\begin{tabular}{|l|l|l|l|}
\hline \multirow{2}{*}{ Исследуемые показатели крови } & \multicolumn{3}{|c|}{ Результаты в группах } \\
\cline { 2 - 4 } & \multicolumn{1}{|c|}{ Основная $(\mathrm{n}=39)$} & \multicolumn{1}{|c|}{ группа 1 $(\mathrm{n}=17)$} & \multicolumn{1}{|c|}{ группа 2 $(\mathrm{n}=20)$} \\
\hline Угол $\alpha$ & $96 \pm 0,3^{\circ} *$ & $75 \pm 0,3^{\circ}$ & $74 \pm 0,3^{\circ}$ \\
\hline $\mathrm{A} 10, \mathrm{~mm}$ & $85 \pm 0,4^{*}$ & $47,4 \pm 0,2$ & $48,8 \pm 0,1$ \\
\hline $\mathrm{A} 20, \mathrm{~mm}$ & $96 \pm 0,6^{*}$ & $62 \pm 0,2$ & $65 \pm 0,8$ \\
\hline $\mathrm{MCF}, \mathrm{mm}$ & $83 \pm 0,5^{*}$ & $54,6 \pm 0,2$ & $54,8 \pm 0,4$ \\
\hline
\end{tabular}

Обсуждение. В результате проведенного исследования было установлено, что периферической крови установлено, что в патогенезе развития БКР важное значение отводится процессам изменения процессов свертывания в крови и изменениям динамики процессов по изменению вязкости и упругости формирующегося сгустка. Так, при исследовании ТЭГ цитратной плазмы крови у пациентов с БКР перед выполнением операции была выявлена гиперкоагуляционная активность, что подтверждалось резким увеличением индекса коагуляции, тромбодинамического потенциала, макси- 
B. В. Масляков и др. Изменения показателей тромбоэластограммы при базальноклеточном раке кожи в послеоперационном периоде

мальной амплитуды и эластичности сгустка, по сравнению с данными обследованных без выявленной патологии. Операция, проведенная пациентам с БКР, не способствовала нормализации показателей ТЭГ. Этот факт следует принимать во внимание при выборе лечения больных с БКР. При этом, в группе обследованных с фибромами кожи, показатели ТЭГ не изменялись и существенно не отличались от результатов, полученных в группе обследованных без выявленной патологии.

\section{Выводы}

1. В патогенезе развитии базальноклеточного рака кожи отводится важное значение в процессе изменения процессов свертывания в крови и изменениям динамики процессов по изменению вязкости и упругости формирующегося сгустка.

2. Выявленные изменения характеризуются гиперкоагуляционной активность.

3. Выполнение оперативного лечения не приводит к восстановлению показателей тромбоэластограммы цитратной плазмы крови у пациентов с базальноклеточным раком кожи.

\section{Литература}

1. Дерматоонкология / под ред. Г. А. Галил-Оглы, В. А. Молочкова, Ю. В. Сергеева. M., 2005. C. 332-368.

2. Масляков В. В., Власенко Ю. Б., Дралина О. В. Патофизиология изменений иммунного статуса у пациентов с плоскоклеточным раком кожи в процессе оперативного лечения // Практическая медицина. 2015. № 6. С. 80-84.

3. Состояние иммунитета у пациентов с базальноклеточным раком кожи / В. В. Масляков [и др.] // Пермский медицинский журнал. 2014. № 6. С. 52-58.

4. Лечение базальноклеточного рака кожи на современном этапе / Т. Е. Сухова [и др.] // Альманах клинической медицины. 2008. № 18. С. 14-21.

5. Хадырев С. А., Погосян А. А., Харатишвили Т. К. Лечение плоскоклеточного рака кожи (обзор литературы) // Вестник РОНЦ им. Н. Н. Блохина. РАМН. 2003. № 2-1. C. 69-72.

\section{CHANGES IN TROMBOELASTOGRAMMA INDICATORS IN CASE OF BAZAL CELL SKIN CANCER DURING THE POST-OPERATIVE PERIOD}

\section{Maslyakov Vladimir Vladimirovich}

Doctor of Medical Sciences, Professor, Vice-Rector for Scientific Work of Private Educational Institution of Higher Education "Saratov Medical University "Reaviz"

410012, Saratov, Russia, Verkhnii rynok st, Building 10

E-mail: maslyakov@inbox.ru

\section{Grebnev Dmitry Yuryevich}

MD, Associate Professor

Head of the Department of Pathological Physiology

of the Federal State Budgetary Institution of Higher Education,

Ural State Medical University

620028, Yekaterinburg, Russia, Repin st, 3

E-mail: usma@usma.ru

Kim Larisa Mikhailovna

graduate student of the Department of Clinical Medicine of the Private Educational Institution of Higher Education "Saratov Medical University "Reaviz"

410012, Saratov, Russia, Verkhnii rynok st, Building 10

E-mail: saratov@reaviz.ru 
Shabaeva Zulfiya Iskanderovna

Graduate student of the Department of Clinical Medicine of the Private Educational Institution of Higher Education "Saratov Medical University "Reaviz"

410012, Saratov, Russia, Verkhnii rynok st, Building 10

E-mail: saratov@reaviz.ru

The paper is based on the analysis of disease course in 76 patients with various formations of skin who participated in the research of a tromboelastogram of blood plasma. As a result of the study, it was found that in the pathogenesis of the development of basal cell skin cancer the processes of coagulation in the blood and changes in the dynamics of processes by changing the viscosity and elasticity of the forming clot are important. In the conducted study of indicators of blood plasma tromboelastogram taken from patients suffering from basal cell skin cancer, hypercoagulation syndrome was noted before the start of the operation, which was confirmed by a sharp increase in the coagulation index, thrombodynamic potential, maximum amplitude and elasticity of the clot. The implementation of surgical treatment does not lead to the restoration of these indicators, all this should be taken into consideration in the treating the patients with this pathology.

Keywords: basal cell skin cancer, thromboelastogram. 